\title{
Ectopic hyperparathyroidism due to an auto-transplanted parathyroid gland
}

\author{
Ko Harada ${ }^{1}$ and Fumio Otsuka ${ }^{2}$ \\ ${ }^{1}$ Okayama University Graduate School of Medicine Dentistry and Pharmaceutical Sciences \\ ${ }^{2}$ Okayama Daigaku - Shikata Campus
}

May 6, 2020

\begin{abstract}
Although parathyroid tissue auto-transplantation is useful for preventing hypoparathyroidism during thyroidectomy, hyperparathyroidism may occur due to proliferation of the transplanted parathyroid tissue. Hyperparathyroidism due to the autografted parathyroid gland should be suspected in patients who undergone parathyroid auto-transplantation.
\end{abstract}

\section{Key Clinical Message}

Hyperparathyroidism due to the autografted parathyroid gland should be suspected in patients who undergone parathyroid auto-transplantation.

\section{Case Presentation}

A 65-year-old woman was referred to our hospital because of hypercalcemia. She had undergone total thyroidectomy for thyroid cancer 30 years prior along with left-sided parathyroid auto-transplantation in her neck, without any family history of endocrine diseases. Physical examination showed a surgical scar on the left side of her neck (Fig. 1 ). Her serum calcium, phosphate, and intact parathyroid hormone levels were $11.3 \mathrm{mg} / \mathrm{dL}, 3.4 \mathrm{mg} / \mathrm{dL}$, and $170 \mathrm{pg} / \mathrm{mL}$, respectively. Tc-99m-MIBI demonstrated increased uptake in the autograft in the left supraclavicular region (Fig. 2 ). Based on these findings, primary hyperparathyroidism due to the autografted parathyroid gland was strongly suspected. Although parathyroid tissue autotransplantation is useful for preventing hypoparathyroidism during thyroidectomy, hyperparathyroidism may occur due to proliferation of the transplanted parathyroid tissue $(1,2)$. This case suggests that long-term regular monitoring of serum calcium levels may be necessary after parathyroid auto-transplantation even in patients without multiple endocrine neoplasia.

Figure Legend

Figure 1: On physical examination, a surgical scar on the left side of her neck was observed.

Figure 2: Tc-99m-MIBI demonstrated increased uptake in the autograft in the left supraclavicular region (arrowhead).

Author Contribution: Ko Harada contributed to patient care, writing the manuscript, and discussion. Fumio Otsuka revised the manuscript.

Funding: None.

Conflict of interests: The authors declare no conflicts of interest in association with this study.

Acknowledgement: None 


\section{References}

1. Senapati A, Young AE. 1990. Parathyroid autotransplantation. Br J Surg 77:1171-1174.

2. Kim BK, Lee J, Sun WY. Recurrent hyperparathyroidism due to proliferation of autotransplanted parathyroid tissue in a multiple endocrine neoplasia type 2A patient. 2016. Ann Surg Treat Res91:145148.

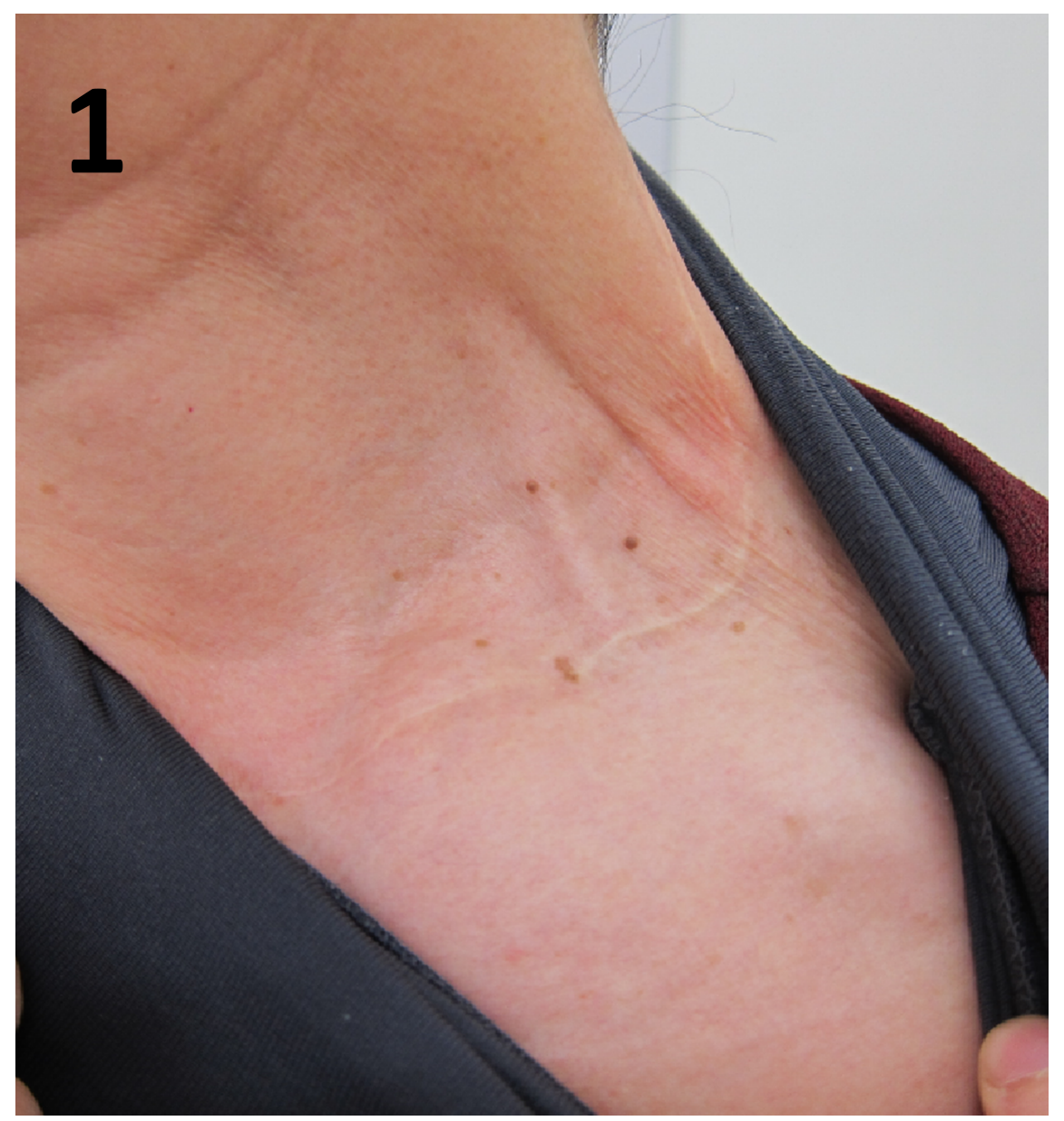




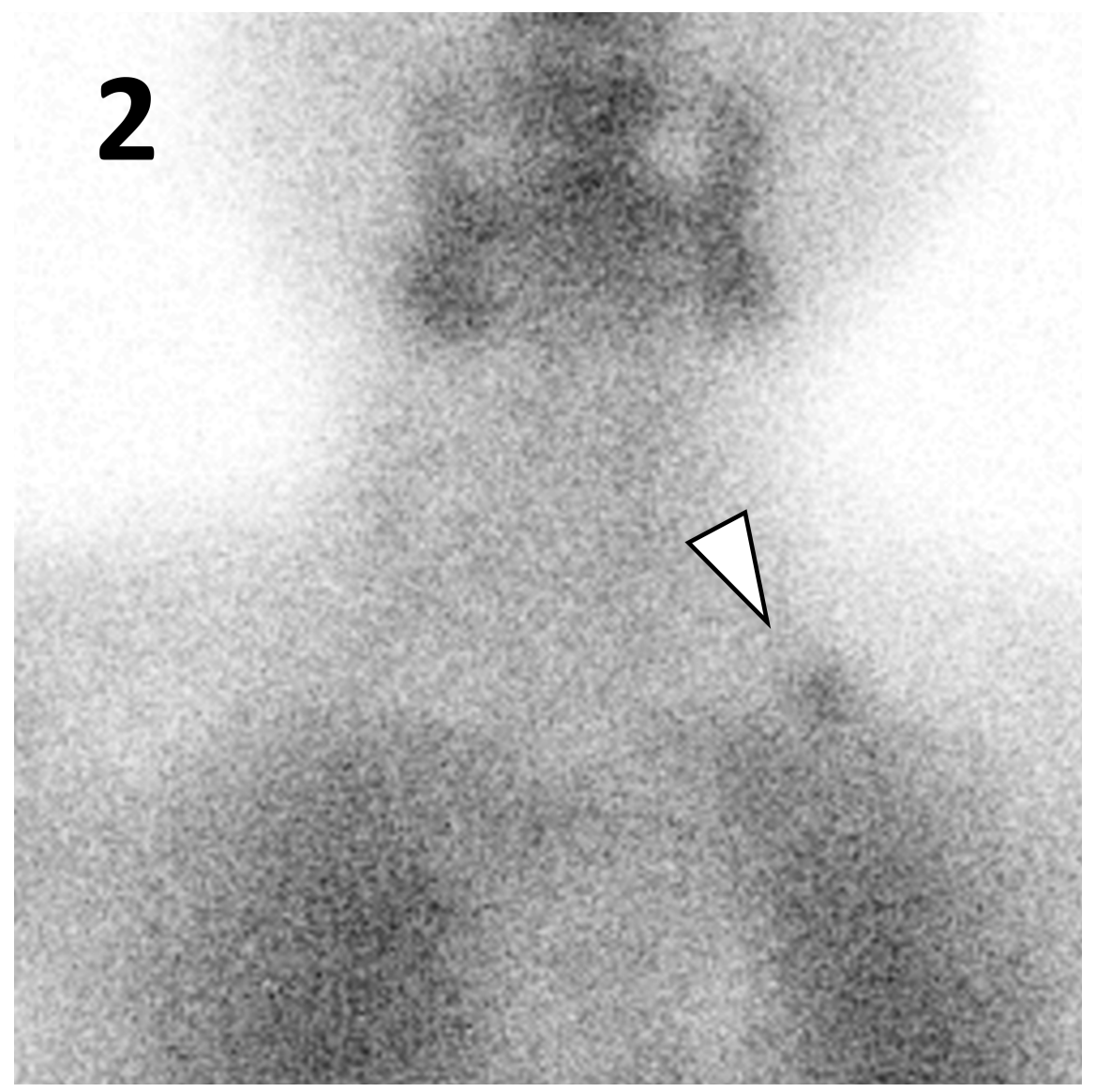

